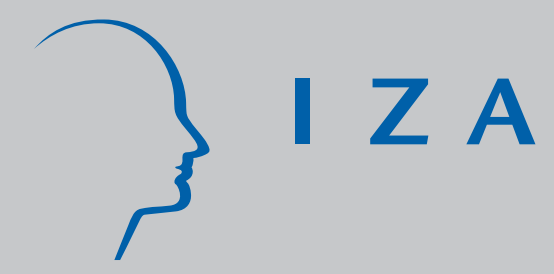

IZADP No. 2576

Stuck in the Slow Lane: Traffic Composition and the Measurement of Labor Productivity in the U.S. Trucking Industry

Kenneth D. Boyer

Stephen V. Burks

J anuary 2007 


\title{
Stuck in the Slow Lane: Traffic Composition and the Measurement of Labor Productivity in the U.S. Trucking Industry
}

\author{
Kenneth D. Boyer \\ Michigan State University \\ Stephen V. Burks \\ University of Minnesota, Morris \\ and IZA
}

Discussion Paper No. 2576

January 2007

IZA

P.O. Box 7240

53072 Bonn

Germany

Phone: +49-228-3894-0

Fax: +49-228-3894-180

E-mail: iza@iza.org

Any opinions expressed here are those of the author(s) and not those of the institute. Research disseminated by IZA may include views on policy, but the institute itself takes no institutional policy positions.

The Institute for the Study of Labor (IZA) in Bonn is a local and virtual international research center and a place of communication between science, politics and business. IZA is an independent nonprofit company supported by Deutsche Post World Net. The center is associated with the University of Bonn and offers a stimulating research environment through its research networks, research support, and visitors and doctoral programs. IZA engages in (i) original and internationally competitive research in all fields of labor economics, (ii) development of policy concepts, and (iii) dissemination of research results and concepts to the interested public.

IZA Discussion Papers often represent preliminary work and are circulated to encourage discussion. Citation of such a paper should account for its provisional character. A revised version may be available directly from the author. 


\section{ABSTRACT \\ Stuck in the Slow Lane: Traffic Composition and the Measurement of Labor Productivity in the U.S. Trucking Industry}

Mirroring the railroad industry of the 1940's and 1950's, the trucking industry today appears to be achieving impressive productivity gains. But it is easy to confuse true productivity advances in transportation industries with changes in ton-miles per unit of input that are due simply to changes in the composition of traffic, as initially happened with the mid-20th century U.S. railroads. This is due to the fact that transportation has vastly different productivities in different settings - for example, when moving long haul versus short haul traffic - and the measurement of changes in physical productivity can be overwhelmed by even subtle changes in the traffic mix. After controlling for endogenous changes in the composition of truck traffic, we find that trucking has in fact been a lagging sector of the U.S. economy over the period of our data, 1982-1997, with observed productivity changes much more likely due to changes in speed limits and the dimensions of vehicles than adoption of information technology. Our finding of a slow improvement in the physical productivity of trucking inputs does not deny the real improvements in the quality of trucking services (reliability, predictability, speed, order tracking, etc.) that have taken place in the last quarter century. But as in other service industries, true physical productivity improvements in trucking are hard to find.

JEL Classification: L92, D24, C43

Keywords: labor productivity, physical productivity, nominal versus real productivity, ton-mile, transportation, trucking industry, VIUS, traffic mix, long haul, short haul, service quality

Corresponding author:

Stephen V. Burks

Department of Economics

University of Minnesota Morris

600 East 4th Street

Morris, Minnesota 56267

USA

E-mail: svburks@morris.umn.edu 


\section{Introduction ${ }^{1}$}

Deregulation and the logistics revolution have transformed the American economic landscape over the last thirty years. At the heart of the logistics revolution has been an apparently dynamic trucking industry. As the price of transportation and the cost of assembling loads plummeted, the quantity of freight and the average distance of freight movements increased. The trucking industry’s adoption of information technology has been well documented and occurred simultaneously with the removal of government restrictions and the rapid increase in freight ton-miles.

This picture of a dynamic industry, using information technology and achieving impressive cost reductions is reminiscent of the way the US railroad industry was initially viewed in the post World War II era. Soaring railroad ton-miles per worker-hour in the 1940's and 1950's occurred at the time that the industry was replacing steam with diesel locomotives. Costs per ton-mile declined rapidly. The idea that the sector had rapidly improving productivity affected labor negotiations within the railroad industry, and public policy towards it. But a famous study by academic economists (Meyer et al., 1973) demonstrated that the rapid productivity improvements were mostly an illusion, due to a change in traffic composition rather than the adoption of new production techniques. Traffic shifts in the 1950's and '60's left

\footnotetext{
${ }^{1}$ We gratefully acknowledge the assistance of the U.S. Census Bureau, which went to a special effort to
} supply the older VIUS microdata sets. Essential research assistance was received from Andrea Hannan, Josephine Myers-Kuykindall, Katie Polinder, Rebecca Schlafer, and Andrew Anderson. Helpful comments were received from Thomas Hubbard and participants at the MSU applied economics workshop and the International Industrial Organization Conference. Burks also gratefully acknowledges support from the Sloan Foundation’s Trucking Industry Program. Errors are the responsibility of the authors. 
railroads with a preponderance of traffic like coal, where ton-miles per worker-hour were high, as trucks took short haul and less dense traffic, where ton-miles per worker-hour were much lower. The loss to trucks of traffic that was costly to handle led to increases in aggregate tonmiles per worker-hour without any changes in operational efficiency.

This paper argues that a similar scenario is playing out in the trucking industry today. Unlike most service or manufacturing industries, transportation industries offer the advantage that there is a standard measure of physical output (ton-miles) that can be aggregated across many different types of operations. But this benefit carries a parallel cost. Precisely because such aggregations are possible, the measurement of productivity in transportation industries is highly sensitive to traffic composition, and to be valid, measurements of productivity changes must control for potential changes in the traffic mix.

Examples of the importance of controlling for traffic composition when measuring transportation productivity are provided by two recent papers that attempt to draw lessons from trucking productivity changes for the broader economy. One attempts to measure the effects of increases in public capital (Fernald, 1999.) Another tries to document the effect of the adoption of information technology (Hubbard, 2003). Fernald finds that transportation industries, of which trucking is by far the largest part, had unusually large productivity increases in period from 1953-1973. Hubbard finds that the use of on-board computers increases productivity of trucks by double-digit amounts, using data from 1992 and 1997. Hubbard's work received considerable notice because it was the first to find significant physical productivity improvements as a result of the adoption of information technology, in contrast to the quality improvements that are the unquestioned (albeit hard-to-measure) result of computerization. 
The finding of large productivity improvements in a service industry like transportation appears to contradict the logic that the pace of productivity improvement should be low in service sectors (Baumol, 1967, 1968, 1972.) Indeed, the Baumol hypothesis seems to be especially compelling in trucking. Trucking is transparently simple. A truck requires a single driver. Without the driver, there is no production. A second driver never operates the vehicle simultaneously with the first, and one driver never operates two trucks at one time. In order for labor productivity to increase in trucking, then, trucks and their drivers must either travel farther in a year while loaded, or carry more tons in their loads. The dimensions and weight limits of a truck are fixed by law, as are speed limits and hours of service. The scope for getting more tonmiles per truck per year by the classic manufacturing method—substituting capital for labor through automation —appears to be modest at best in this industry.

In this paper, we will analyze microdata from the quinquennial Vehicle Inventory and Use Survey (VIUS) to show that failing to account for systematic changes in the composition of truck traffic has a significant impact on the magnitude of measured trucking industry productivity. We focus on the single most common type of heavy trucking equipment-the standard enclosed van pulled by a heavy truck tractor. Over a fifteen year period following trucking deregulation for which comparable operational data are available in the VIUS, 19821997, we estimate how the annual ton-miles per truck-and-driver combination varies with variations in the operational characteristics of these rigs. The results permit us to compare the fleet-level average productivity of like vehicles over time, controlling for changes in traffic composition, something that is impossible to do if output is measured using a simple aggregation of ton-miles, or if productivity is estimated from the financial accounts of trucking firms using flexible forms. 
The focus on vehicles rather than firms is an engineering approach to measuring production functions. Using this approach, we will argue that the traffic mix changes we document are endogenous. This in turn suggests that the causality between measured productivity changes over time and cost changes in trucking is largely from costs to measured productivity, rather than from higher productivity to lower costs. There was a large increase in long-distance relative to short-distance trucking over the period from 1977 to 1997, as shown in Table 3 below (see also, Burks et al. 2004). This shift was driven primarily by a decline in the price for trucking services that occurred during this period. The price of trucking services declined due to a reduction of regulatory rents and sharp cuts over this period in the price of inputs, notably drivers’ wages and fuel prices. (Belzer 1995, Belman and Monaco 2001, Monaco and Brooks, 2001, Rose 1985).

As Table 3 below shows, ton-miles per truck are the highest in long haul markets. Long haul trucks run many more miles per year than do those involved with short haul transportation. because they spend a higher proportion of their total operational time traveling at high speeds on intercity highways. They also tend to stay relatively fully loaded; the cost of loading short haul and long haul units is similar, but the cost savings from keeping a long haul one fully loaded is higher. The demand for trucking services is derived from the geographic distribution of demands for the products trucks haul, and short haul lanes were already relatively intensely served, so when the price of all trucking services dropped, long haul is exactly where the demand for trucking grew most rapidly. The result has been an increasing proportion of long-distance traffic, which in turn created the appearance that labor productivity had risen faster than was actually the case. This bias in productivity measures due to endogenous changes in output 
composition is an example of the aggregation issues in heterogeneous populations that are summarized in Blundel and Stoker (2005).

We will show in this paper that physical productivity in trucking has indeed increased, but at a slower rate than in the rest of the economy as a whole. The primary sources of increased productivity are an increase in miles per truck, due in part to increases in speed limits, and the increasing length of truck trailers, which has increased the interior volume of the average enclosed van over the period of our study, partly offsetting a trend we also document, to less densely-loaded trailers.

Section 2 lays out our method for calculating the productivity of driver-and-vehicle combinations from the sub-measures of miles per year, tons per loaded movement, and the likelihood of having a loaded movement. In this section we also briefly describe the data, and our method for measuring traffic composition and separating composition effects from true changes in physical productivity. Section 3 provides the results of our measurement of trends in productivity sub-measures and traffic composition in the trucking industry at the end of the twentieth century. Section 4 summarizes the argument and offers some caveats and conclusions. A Data Appendix describes the VIUS data, and how it was utilized, in more detail. 


\section{2: Measuring Productivity Trends at the Vehicle Level}

The classic physical output measure in transportation industries is ton-miles per year, defined for data on vehicle movements as the product of tonnage and mileage summed over all truck movements in a year. $^{2}$

$$
Q^{y}=\sum_{i=1}^{N^{y}} T_{i}^{y} M_{i}^{y}=\sum_{i=1}^{N^{y}} L_{i}^{y} T_{i}^{y} M_{i}^{y}
$$

Where $Q^{y}=$ ton-miles in year $y$,

$T_{i}^{y}$ is the tons of freight carried by a truck on movement $i$ in year $y$,

$M_{i}^{y}$ is the miles that freight was carried by a truck on movement $i$ in year $y$,

$N^{y}$ is the number of truck movements in year $y$, and

$L_{i}^{y}$ is a binary variable indicating whether movement $i$ in year $y$ was loaded or empty, used when the data include both.

The physical productivity of the industry is measured in ton-miles per unit of input. In the trucking industry, the standard method of production for non-specialty heavy freight movements is one truck-tractor pulling an enclosed van. The characteristics of the basic enclosed van are determined primarily by limits imposed by state and federal law (TRB, 2002). Notable changes in the regulations regarding size over the period in question have been the Federal requirement that all states allow twin 28' trailers (which may be substituted for a single longer van) on Federal Aid highways and the gradual increase in single trailer lengths, from 45' to 53', based on aggressive implementation of grandfather rights and state lobbying.

\footnotetext{
${ }^{2}$ A parallel formulation, summing the product of weight and distance for each shipment over all shipments,
} is appropriate when the data is shipment-based, as opposed to vehicle-based. 
While for some lighter commodities the limits on trailer usage are determined by the physical volume of the van, for denser goods the maximum gross vehicle weight (GVW) is the limiting factor. Maximum vehicle weights are the joint responsibility of state and federal governments, with the Federal law providing (at various times) both a floor and a ceiling on the maximum allowable weights. About a third of states opt for higher limits within all or part of their own borders, and these regulations too have changed over time. The most common tractortrailers operate in a configuration that permits them to cross state boundaries, and are governed by the Federal limits. As trucks were gradually getting longer, there also were changes in weight limits, as the maximum gross vehicle weight for most Eastern states and some of the Midwest was raised from 73,280 lbs. to a common 80,000 lbs. national standard. There has been a small movement towards trucking with triple trailers or extra-long doubles, but legal restrictions and the economic advantages of the loading flexibility gained by operating with a basic enclosed van have limited the expansion of longer combination vehicles. Our representative sample of trucks contained only a handful of longer combination vehicles—-too few to include the effects of longer combination vehicles in our analysis.

As noted previously, the VIUS data allow us to track the annual ton-miles per truck across the entire fleet of relevant vehicles, which is calculated in equation (2) as ton-miles divided by the number of trucks in a fleet, or:

$$
q^{y}=\frac{\sum_{j}^{n}\left(\sum_{i}^{N^{y}} T_{i}^{y} M_{i}^{y}\right)}{n}=\frac{\sum_{j}\left(\sum_{i}^{N^{y}} L_{i}^{y} T_{i}^{y} M_{i}^{y}\right)}{n}
$$

where variables are as defined in (1), plus $j$ indexes trucks in a fleet of size $n$, $i$ indexes movements of each truck in the fleet, and and $q^{y}$ measures ton-miles per truck in year $y$. 
The VIUS data are derived from a survey sent every five years by the Census Bureau to a random sample of truck owners in the U.S. Respondents provide summary information on the manner in which the sampled vehicle was utilized over the previous year. ${ }^{3}$ Thus, data are not available on individual movements of trucks and we cannot calculate ton-miles by directly applying the definition of equation (2). Instead we follow the universal convention of estimating the average ton-miles per vehicle in a given year with the following approximation:

$$
q^{y}=\frac{\sum_{j=1}^{n^{y}} l_{j}^{y} t_{j}^{y} m_{j}^{y}}{n^{y}}
$$

where

$q^{y}$ measures the average ton-miles per truck-and-driver combination in year $y$, $l_{j}^{y}$ is the proportion of trips that truck $j$ operated loaded during year $y$, $t_{j}^{y}$ is the average tons hauled by vehicle $j$ in year $y$ when the truck operated with a load, $m_{j}^{y}$ is the number of miles driven by vehicle $j$ in year $y$, and $n^{y}$ is the number of trucks in the year $y$ population.

As Table 3 (below) shows, trucks have very different productivities depending on the setting in which they are used. The data allow us to identify the primary range of operations of each sampled truck in each year in the following three categories: 1) Range: local (under 50 miles), short distance (50 to 200 miles), and long distance (in excess of 200 miles); 2) Sector: for hire, manufacturing, retailing, wholesaling, or other; and 3) Commodity carried: farm products, processed food, building materials, paper, chemicals, primary metal products,

\footnotetext{
${ }^{3}$ See the Data Appendix for further details.
} 
fabricated metal products, machinery, transportation equipment, furniture, textiles, forest products, petroleum and plastics products, and other.

With each truck in our data set having three independent descriptors (three ranges, five sectors, and fourteen commodities), each vehicle falls into one of 210 distinct categories. This allows us to rewrite equation 3 on the basis of aggregating over these segments. Thus, for the average truck in year $y$ we have:

$$
q^{y}=\sum_{k=1}^{210} l_{k}^{y} t_{k}^{y} m_{k}^{y} w_{k}^{y}
$$

where

$q^{y}$ measures the average ton-miles per truck-and-driver combination in year $y$, $l_{k}^{y}$ is the proportion of movements of trucks in traffic segment $k$ in year $y$ that were operated loaded,

$t_{k}^{y}$ is the average number of tons carried by trucks devoted to traffic segment $k$ in year $y$, when they operate loaded,

$m_{k}^{y}$ is the average number of miles per year traveled by trucks in traffic segment $k$ in year $y$, and $w_{k}^{y}$ is the proportion of all truck traffic in year $y$ that is in traffic segment $k$.

Every five years a new random sample of trucks is selected for the VIUS survey. Since the median life of a truck is about the same as the sampling frequency, little is lost by having a repeated cross-section, as opposed to a true panel, of vehicles. Our procedure is to do a pooled cross-section/time-series survey regression for each of the components of physical productivity—miles per truck, tons per truck, and the probability of being loaded. ${ }^{4}$ We regress the reported partial productivity measure for each truck (tons, miles, and proportion trips

\footnotetext{
${ }^{4}$ By "survey regression" we mean that each observation is weighted by the number of trucks in the
} population it represents, according to the stratified random sampling scheme used by the Census Bureau. 
operated with a load) against the elements of the classification describing it, including appropriate time dummies and time-interaction effects. We then estimate the average ton-miles per truck in each year—for the entire fleet of tractors pulling enclosed vans—as the product of each of the predicted components of the measure (the predicted values of tons, miles, and the proportion of time loaded) and the actual percentage of traffic falling into each classification in the given year.

$$
\hat{q}^{y}=\sum_{k=1}^{210} \hat{l}_{k}^{y} \hat{t}_{k}^{y} \hat{m}_{k}^{y} w_{k}^{y}
$$

Our procedure for controlling for cumulative traffic composition effects over the period

of our data follows in a straightforward fashion. We simply compare $\hat{q}^{1997}$ with

$$
\sum_{k=1}^{210} \hat{l}_{k}^{1997} \hat{t}_{k}^{1997} \hat{m}_{k}^{1997} w_{k}^{1982}
$$

Formula (6) gives us a measure of the ton-miles of trucks in 1997, under the counterfactual assumption that the traffic composition had been held constant across the 210 segments as it occurred in 1982.

\section{3: Productivity Trends at the Vehicle Level}

Table 1 shows the results of estimations for each of the three partial productivity measures over the period 1977-1997. The year from which each observation was drawn is indicated by dummy variables, and the base year in the regression is 1982. The range in which the vehicle was primarily operated is indicated by one of two dummy variables (50 to 200 miles—short distance, and over 200 miles—long distance), and the base range is local (under 50 
miles). The sector in which the vehicle operated is indicated by one of four dummy variables. The base sector is the residual group (that is, not wholesale, retail, manufacturing, or for-hire.) Each regression also contains fixed effects binary variables identifying the primary commodity carried. The base commodity is "other" (not one of the thirteen more specific commodities listed above, in Section 2). The year variables are interacted with the range of operation (local, short distance, long distance,) by the sector operating the truck (retail, wholesale, manufacturing, for hire, or other,) and in the case of the regression 3, with the weight of the truck by the length of the enclosed van represented by the record.

The first order effects visible at the top of Table 1 are that, relative to local movements, trucks engaging in long haul operations travel many more miles per year, are loaded more heavily, and are less likely to be involved in an empty movement. Longer trailers carry on average more freight than short ones. All of the listed sectors travel more miles and with fewer empty movements than the residual sector, but their freight tends to be lighter.

Equation 1 of Table 1 is estimated in logs to account for the very large differences in reported mileage and because the log form provided a superior fit. Miles were reported in 1977, but the other key partial productivity measures were not, and thus equation 1 extends the regression results five years earlier than do the regressions for the other measures, for which the data series start in $1982 .^{5}$ Equation 1 has an excellent fit, indicating that miles traveled have a systematic relationship with sector, range, and commodity.

\footnotetext{
${ }^{5}$ Thus the regressors y77, pshort77, plong77, retail77, wholes77, manuf77, and forhire77 are all missing
} from columns (2)-(4). This is also why our core productivity analysis only covers 1982-1997, even though we make use of the VIUS data set for1977. 
Equation 2 shows that the probability of operating with a load is also strongly affected by commodity, range, and sector. The first order effects show that a large jump in the marginal probability of operating with a load occurred between 1982 and 1987, followed by a dip in the probability in 1992 and a restoration of the 1987 levels by 1997, though the differences are statistically insignificant among the latter three years.

Equations 3 and 4 of Table 1 both report regressions of the net weight of the average load of a truck during a year against the descriptors of the truck usage. Equation 3 includes a measure of the length of the truck, while equation 4 eliminates these variables. According to the estimated coefficients, each additional foot of cargo length increased the predicted load by 449 pounds in 1982, but this amount was lower in later years.

It is difficult to spot trends from the regressions in Table 1 since time enters in interacted form and the effect of time must be constructed from all of the time-varying effects that differ by sector, range, and commodity. Therefore, to analyze these trends, a forecast is made for each year for every combination of commodity, range, and sector in each of the years for which data are available. Conditional on our regression specification, for each output measure these forecasts capture what is systematic in the relationship between the fleet's operational characteristics and its output results. Using equation 5 , a weighted average for each of these forecasts is then made for each year, using the reported miles traveled in each group as the weights. These weighted averages estimate the operational results achieved by the entire fleet (of heavy truck tractors pulling enclosed vans), by each measure for each year, as a function of the fleet's operational characteristics in that year. In each case we add a second line using equation 6, which repeats the forecast and estimate, but with the effects of changes in the traffic mix from its composition in 1982 removed. 
The results of these calculations are shown in Table 2, which presents our core evidence. The first block of results shows that there clearly were improvements in the average probability of operating with a load. The current year weighted average increased from $78.6 \%$ of trips operated with full loads in 1982 to $85.4 \%$ in 1997 . The improvement was steady over the period, representing an average annual improvement of $0.54 \%$. However, nearly half of this improvement was due to a shift in traffic composition, shifting from segments that have relatively low load factors to those with relatively high levels of loaded runs. Had the traffic composition been held constant at 1982 levels, the average annual improvement would have been only $0.29 \%$ annually.

The largest increases in the rows of Table 2 for our three measures of partial productivity are those associated with increases in miles per truck, with the average enclosed van increasing the number of miles driven per year from 63,628 miles to 82,053. This represents an annual percentage increase of $1.58 \%$ per year. However, again more than a third of this was due to a shift in the composition of traffic. Had the proportion of truck traffic in long distance versus local movements, and related shifts in the proportion of traffic in particular sectors and commodities, not taken place, the average annual increase in miles would have been measured at only $1 \%$. It should be noted however, that this amount surely understates the true magnitude of traffic composition effects since it does not allow for shifts within the over-200 mile range. To the extent, for example, that lower trucking prices led to the substitution of 200 mile hauls by 600 mile movements, our traffic composition measure will not pick up this effect. ${ }^{6}$

\footnotetext{
${ }^{6}$ The importance of shifts in the open-ended range is suggested by a regression (not reported here, but available from the authors) that repeated the same analysis as in Table 2 for the years 1992 and 1997 when data on a
} 
The most interesting trend in Table 2 is in the weight of cargo carried in enclosed vans. Trucks over this period were gradually lengthening to their current standard length of 53 feet and some states liberalized their weight laws. Over this period, the average weight of cargo per truck was essentially flat, despite more liberal regulations. However, this regulatory change hides a substantive trend: had trucks stayed the same length as they were in 1982 and had the relationship between loading and trailer length remained constant, there would have been a reduction in the average load at a rate of $0.59 \%$ per year. Also of interest is that this decline was exacerbated by traffic composition effects: had traffic composition been held constant at it 1982 values, the average load would have declined over this period at only .25\% per year, or less than half the rate.

There are two logical possibilities for why trucks carried smaller loads when controlling for length over this period-either freight is getting less dense as the economy moves away from heavy manufacturing towards lighter goods, or each truck is less completely loaded. The latter might occur, for example, if there is a move away from dispatching trucks based on whether they are full in favor of a system of scheduled deliveries. The data do not reveal the relative

finer break-down of operating ranges was available. In these years, the ranges of truck operation were broken down into local (under 50 miles), short (50-100 miles,) short-medium (100-200 miles,) long-medium (200-500,) and long (500 miles or more one way.) With this finer breakdown of operating ranges, there is still a strong relationship between the miles per truck and operating ranges, with trucks operating in the two longest ranges generating more than $150 \%$ more miles per year than trucks devoted to local service. Between 1992 and 1997 there was an increase in distances operating by trucks operating in all ranges, and the increases were increasingly larger in the long distance ranges. While only in the case of long distance trucking (over 500 miles) did the increase approach significance, we would expect greater statistical significance were we able to include earlier years. 
importance of these factors. What is clear, however, is that the reduction in the weight carried in trucks makes it appear that the partial physical productivity per worker, as measured by weight hauled, would have declined over this period, had the average length of trucks not increased.

The last two parts of Table 2 construct ton-miles as the product of the forecasted components, miles, fraction of runs loaded, and average load if not empty. Again, there are two weighting schemes—one tracking the current year traffic composition and one holding traffic composition constant at 1982. The difference is even more dramatic than for the components. Ton-miles per truck increased at an average annual rate of 1.85\% per year between 1982 and 1997, but .54 percentage points can be traced to changes in traffic composition. If each of the 210 range/sector/commodity combinations had the same proportion of traffic in 1997 as it had in 1982, we would expect ton-miles per truck to have increased by only $1.31 \%$ annually.

An even larger distinction is found if we hold constant the length of trucks at their 1982 level. Allowing the actual changes in traffic composition, annual ton-miles per truck would have increased by $1.33 \%$. Holding traffic composition constant as well, the increase in productivity would have been only $.84 \%$ per year.

From the above calculations we can also directly estimate the proportion of the productivity growth in the U.S. truck fleet that is due to the increase in the length of basic enclosed vans. We compare the annual growth rate estimated with current (i.e.growing) trailer lengths, to that obtained when trailer lengths are held constant at their 1982 levels. If we do this for the case in which the traffic mix is also allowed to change over time, we compare $1.85 \%$ per year to $1.33 \%$, which says .52 percentage points, or $28 \%$ of the observed increase, came from trailer length increases. If we do this for the case in which the traffic mix is held fixed at its 1982 composition, we compare $1.31 \%$ per year to $.84 \%$, which says .47 percentage points, or $36 \%$ of 
the observed increase, came from trailer length increases. We conclude that about one third of the growth rate in trucking productivity over this period was due to increasing trailer lengths.

Table 3 gives a sense of why traffic composition effects are so large in the trucking sector. Column (1) shows the 1982 ton-miles per truck for different sectors, ranges, and commodities. By far the largest difference is within range, with trucks operating in long-distance movements producing more than 6 ton-miles per year for each ton-mile produced by trucks operating locally. Differences in sector are not quite as large, but for-hire operators of trucks manage to produce about twice the ton-miles per truck compared with operators in the "other" category. Carriers who deal with furniture are not as productive as those who carry wood products, again as measured by the ton-mile criterion.

Over the 15 year period for which this study has complete productivity data, the different ranges and sectors improved their productivity at very different rates. There was also a concurrent shift in the distribution of traffic as the proportion of long haul movements increased at the expense of local and short haul, and the for-hire sector expanded by taking traffic that had formerly been handled by the retail and wholesale sectors. Within the category of generalpurpose basic enclosed vans, trucks primarily hauling different commodities also have important differences in physical productivity, although the differences are not as large as for the other descriptors. Since commodity shipments are growing at different rates, and changes in characteristics of hauls are similarly shifting, the measurement of physical productivity is also affected by the commodity composition of traffic.

All of these numbers should be compared with average productivity changes in the economy as a whole, which averaged $1.8 \%$ per year over this period. It is clear that trucking has been a lagging sector, like the railroad industry of the 1950's and '60's, a fact that has been 
masked by changes in the composition of truck traffic. The productivity increases that have occurred can be traced primarily to two factors - the increasing length of trucks over this period and an increase in miles per truck. The timing of latter effect is consistent with the increase in miles per truck being significantly due to an increase in speed limits that occurred in the mid 1980’s and again in the mid 1990’s.

\section{4: Conclusion}

Economic studies of productivity growth have favored the transportation industries due to the abundance of data in the sector, and the availability of physical output measures that can be used across firms and industry segments. However, the industry is characterized by extraordinary output heterogeneity, and has significant aggregation problems which, if ignored, can seriously bias results. This paper illustrates the importance of controlling for output heterogeneity when analyzing productivity issues in the transport sector. By controlling for changes in traffic composition, this paper has demonstrated that physical productivity improvements in the trucking industry have been relatively modest. There were small increases in output per truck following 1982, likely due to increased speed limits on U.S. highways, and also increases in productivity due to the increasing lengths of U.S. trucks — the latter offsetting a declining trend in loaded weights for highway freight movements. There have also been small steady increases in the percentage of highway vehicles that operate loaded, presumably due to improved data processing that improves matching loads and drivers. The apparent levels of all of these effects are amplified, however, by changes in traffic composition. If traffic composition is controlled for, productivity differences over time in the industry appear to be quite modest.

The traffic composition effects found in this paper are moreover almost surely underestimated, and perhaps profoundly under-estimated, thus over-estimating the true rate of 
productivity increase. This is due to the fact that we are unable to measure shifts in the traffic composition in the over-200 mile block. There is tantalizing evidence that there have been strong increases in the share of very long distance trucking (more than 500 miles) between 1992 and 1997. This extra traffic composition effect, not captured in this paper, would further reduce the estimate of the true underlying physical productivity increase had its influence been measured.

Several disclaimers about this result should be mentioned. First, our index of productivity is a physical measurement of ton-miles per truck. We use this because it is the standard method in the literature for aggregating output across firms and industry segments, and it is also what can be measured systematically over the time period. However, if the quality of trucking services improved because truck deliveries became swifter or more reliable or more predictable, or if the percentage of deliveries with lost or damaged freight declined, the quality improvement would have contributed a positive increment to productivity growth that our measures would have missed. This is the form of quality enhancement that is assumed to be the payoff due to computerization in studies of the effect of technology adoption in the labor economics literature (DiNardo and Pischke, 1997), and the results of this paper are fully consistent with the view that such quality enhancement is the primary way in which information technology improvements have affected the trucking industry. While we find no evidence of an acceleration of productivity increases as a result of information technology, nothing that we have demonstrated in this paper contradicts the idea that substantial quality improvements in trucking have flowed from the adoption of information technology.

Second, some of the miles per truck since 1977 may have been more productive due to a decrease in circuity that followed the abandonment of route restrictions imposed by economic 
regulation of the trucking industry. There have been no systematic measurement of regulatoryinduced circuity, and our data does not permit us to observe whether truck miles in our earlier data years may have been inflated due to regulatory-imposed routings.

Third, our engineering approach to productivity measurements is vehicle-based, and translates to economic measurements using the assumption that one unit of labor (a driver) is operating each vehicle at a given time. Because the predominant role for labor in the trucking industry is in the truck cab, we believe this is appropriate. However, if there were any systematic improvement over the time period of our study in the labor productivity of support services for truck movements, such as in dispatching, or in corporate overhead functions such as payroll, or in sales work (in the for-hire part of the trucking industry), our measures would not capture it.

Fourth, we should also note that there is disagreement about the extent to which trucks pay the full costs of the highways that they use. (See for example, FHWA, 1998.) To the extent that trucking imposes external costs on other highway users, an increase in trucking productivity may not represent an improvement in social productivity. Socially productive productivity improvements require that trucks be charged their full marginal costs.

In closing, we highlight a potentially important implication of our findings. We have suggested that the demand for trucking services was quite price elastic over the time period of our study, so that lower prices for trucking services led to a higher quantity being demanded, especially in the long haul segments of trucking. The post-deregulation trucking industry is competitive, and passes cost changes (whether positive or negative) through to shippers. If the secular trends in factor prices that led to lower trucking prices in the late eighties and the nineties — the decline in fuel prices and the decline in driver compensation —-were to reverse, this mechanism could also reverse, other things held equal. With rising input prices, at a minimum 
we would expect that the trend we have documented, toward a higher proportion of long haul movements in the traffic mix of the U.S. truck fleet, would not advance further. It is even possible that the traffic mix could start to shift back in the other direction. Since traffic mix changes have been so important in the nominal productivity of the industry, such a change could have significant effects on the nominal productivity delivered by the U.S. truck fleet in the future. 


\section{Data Appendix}

Our data source is the Vehicle Inventory and Use Survey (VIUS, known before 1997 as the Truck Inventory and Use Survey, or TIUS). The VIUS is one of the major benchmark surveys of the Census of Transportation. Every five years a stratified random sample of more than 100,000 truck owners are mailed an extensive survey form, which asks about many characteristics of the vehicle and how it was used during the previous year. The sampling design is based primarily on state-level truck registration information, and every registered owner of any type of truck, from pickups and SUV's to tractor-trailers, is sampled, with the single major exception being owners that are units of government. ${ }^{7}$ Compliance with the survey is legally required under Title 13, United States Code, and, by the same statute, individual responses are confidential. Response rates are typically $75 \%$ or better, and, after any deletions required maintaining respondent confidentiality, an approximately 100,000-case public use microdata set results for each year. Sampling weights are provided to permit inferences about population values.

In the present analysis, we start for each survey year by extracting the subset of "heavy freight vehicles”, as defined in Burks, et al. (2004), from the public use file. These are vehicles that have a body type that can haul freight, that are not used primarily for personal transportation, that have a maximum legal gross vehicle weight (GVW) of at least 26,000 lbs., ${ }^{8}$ and which are

${ }^{7}$ The two biggest groups of vehicles thus excluded are vehicles owned by the USPS and the U.S. military.

${ }^{8}$ This breakpoint demarcates Class VII and Class VIII commercial vehicles from smaller ones, and is the level at which a Commercial Driver's License is required due to the weight of the vehicle alone. In addition, the VIUS survey design uses this weight as a major demarcation, so vehicles with this GVW or greater are sampled 
operated on-road. In 1977, this selection process reduced the full sample of 96,494 cases, representing 26.2 million trucks of all kinds, to a sub-sample of 22,877, representing 1.43 million heavy freight vehicles. In 1997, the selection process reduced the full sample of 104,545 cases, representing 72.8 million trucks of all kinds, to a sub-sample of 44,228, representing 2.13 million heavy freight vehicles.

Next, we further select from the sample those vehicles composed of (1) truck-tractors (2) with diesel engines (3) that were acquired before the sampling year, (4) were still owned by the respondent at the time of the survey, and (5) which primarily pulled semi-trailers of the basic enclosed van type. Restriction (1) eliminates straight trucks, and (2) eliminates the small number of heavy truck tractors that use gasoline or natural gas engines. Data from 1992 and 1997, for which the weeks of operation during the year are separately reported, show that vehicles acquired during the survey year or no longer currently owned are likely to be operated less than the full reporting year, biasing downward their reported annual miles; (3) and (4) eliminate such vehicles.

Interestingly, in conversing with Census officials during this project we discovered an undocumented data transformation they had made: for 1992 and 1997, Census increased the reported annual miles for vehicles used only part of the year to an annualized figure, but only for those vehicles acquired or disposed of during the reporting year, not for those vehicles owned the entire year and just not used the entire time. Apparently this reflected the historical fact that the questionnaire in previous years had asked respondents to calculate their own annualization, and

more heavily than are lighter vehicles, and the average loaded weight, required for ton-mile estimation, is only reported for vehicles above this boundary. 
report it as their actual annual miles, under these circumstances. We decided to eliminate such cases in all years in order to reduce measurement errors in annual miles.

Finally, requirement (5) eliminates truck tractors that are pulling other trailer types, such as flatbeds, reefers (refrigerated vans), and more specialized equipment such as log trailers, dry bulk hoppers, dump bodies, tank trailers, or carhaul trailers. This ensures that, accounting for changes in length and weight from the data, we are comparing like "general purpose” vehicles across the data years. In 1997, this set of restrictions selected 5,363 cases representing 340,980 trucks of the desired type in the population, out of 40,575 cases representing 2.23 million heavy freight vehicles of all types.

Annual mileage was used in this study as reported by each truck owner. The percentage of loaded hauls was calculated as one minus the percentage of trips operated with no load. Average loads were calculated as the reported average weight of a truck with a load minus the average tare weight of the truck. The early years of the questionnaire allow the respondent to report either the empty weight of the truck or of the truck and trailer. Due to this ambiguity in the wording of the question on loaded weights, we limit the analysis to those records with trucks reporting an empty weight of more than 22,500 lbs and calculated net loads greater than 10,000 lbs.

The VIUS data for 2002, while available, are not utilized in the present study because the Census Bureau radically changed the industry and commodity definitions used in the survey, and so the 2002 data is not directly comparable to the earlier data years using our present framework. 


\section{References}

Baumol, W.J., (1967), “The Macroeconomics of Unbalanced Growth: The Anatomy of Urban Crisis,” American Economic Review, Vol. 57, pp.415-426.

Baumol, W.J., (1968), “The Macroeconomics of Unbalanced Growth: Comment,” American Economic Review, Vol. 58, pp.896-897.

Baumol, W.J., (1972), “The Macroeconomics of Unbalanced Growth: Reply,” American Economic Review, Vol. 62, p. 150.

Belman, Dale and Kristen Monaco (2001), “The Effects of Deregulation, DeUnionization, Technology, and Human Capital on the Work and Work Lives of Truck Drivers”, Industrial and Labor Relations Review, Vol. 54, No. 2A, pp. 502-524.

Belzer, Michael, (1995), “Collective Bargaining after Deregulation: Do the Teamsters Still Count?”, Industrial and Labor Relations Review, Vol. 48, No. 4, pp. 636-655.

Blundell, Richard and Thomas M. Stoker, (2005) “Heterogeneity and Aggregation,” The Journal of Economic Literature, Volume XLIII, No. 2, pp. 347-391.

Burks, Stephen V., Kristen Monaco, and Josephine Myers-Kuykindall, (2004), “The Balance between Private and For-Hire Carriage and Trends in the Use of Large Trucks (1977 to 1997)” Journal of the Transportation Research Forum, Vol. 43, No. 2.

DiNardo, John, and Jorn-Steffen Pischke, (1997) “The Returns to Computer Use Revisited: Have Pencils Changed the Wage Structure, Too?” Quarterly Journal of Economics, Vol. 112 (February) pp. 291-303. 
Fernald, John G. (1999), “Roads to Prosperity? Assessing the Link between Public Capital and Productivity, The American Economic Review, Vol. 89, No. 3, pp. 620-638.

Hubbard, Thomas (2003), “Information, Decisions, and Productivity: On Board Computers and Capacity Utilization in Trucking,” The American Economic Review, Vol. 93, No. 4, pp. 1328-1353.

Meyer, John R. et al. (1973), Improving Railroad Productivity: Final Report of the Task Force on Railroad Productivity, (A Report to the National Commission on Productivity and the Council of Economic Advisors, Washington, D.C.)

Monaco, Kristen, and Taggart Brooks, (2001), "Deregulation and Wages in Trucking: A Time Series Phenomenon - A Time Series Approach”, Research in Transportation Economics, Vol. 6.

Rose, Nancy (1986), “The incidence of Regulatory Rents in the Motor Carrier Industry”, Rand Journal of Economics, Vol. 16, No. 3.

Transportation Research Board (2002), Special Report 267: Regulation of Weights, Lengths, and Widths of Commercial Motor Vehicles, (Washington, D.C. National Academies Press.)

United States Bureau of the Census (various years), Census of Transportation: Truck Inventory and Use Survey, (Washington, D.C: U.S. Government Printing Office)

United States Bureau of the Census (various years), Census of Transportation: Vehicle Inventory and Use Survey, (Washington, D.C: U.S. Government Printing Office) 
United States Department of Transportation Federal Highway Administration (FHWA, 1997), 1997 Federal Highway Cost Allocation Study Final Report, (Washington, D.C: U.S. Government Printing Office) 


\section{Table 1}

\section{Survey Regression of partial productivity measures}

Expansion Factor used as probability weights

Year-Base State combinations used as primary sampling units

Pooled Data 1977-1997

\begin{tabular}{|c|c|c|c|c|c|c|c|c|}
\hline & \multicolumn{2}{|c|}{$\begin{array}{c}(1) \\
\text { Ln(Annual Miles) }\end{array}$} & \multicolumn{2}{|c|}{$\begin{array}{l}\text { (2) } \\
\text { Prob. Of Load }\end{array}$} & \multicolumn{2}{|c|}{$\begin{array}{l}\text { (3) } \\
\text { Net pounds of freight }\end{array}$} & \multicolumn{2}{|c|}{$\begin{array}{c}\text { (4) } \\
\text { Net pounds of freight }\end{array}$} \\
\hline & Coef. & Std. Err & Coef. & Std. Err & Coef. & Std. Err & Coef. & Std. Err. \\
\hline$\overline{\text { pshort }}$ & 0.87 & 0.06 & $\overline{-0.01}$ & 0.02 & $\overline{~ 1290.0}$ & 641.5 & 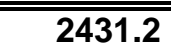 & 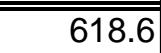 \\
\hline plong & 1.62 & 0.04 & 0.05 & 0.02 & 7062.7 & 1212.1 & 8748.0 & 1168.9 \\
\hline retail & 0.20 & 0.15 & 0.12 & 0.05 & -4871.7 & 1683.0 & -5234.4 & 1459.7 \\
\hline wholes & 0.15 & 0.15 & 0.11 & 0.05 & -3957.2 & 1601.0 & -4064.8 & 1636.3 \\
\hline manuf & 0.20 & 0.14 & 0.13 & 0.05 & -3152.4 & 1733.0 & -3533.9 & 1643.1 \\
\hline forhire & 0.18 & 0.14 & 0.27 & 0.05 & -3820.5 & 1478.1 & -3874.6 & 1419.8 \\
\hline y77 & -0.06 & 0.17 & & & & & & \\
\hline$y 87$ & 0.05 & 0.18 & 0.16 & 0.05 & 7192.6 & 4128.3 & -3235.4 & 1873.5 \\
\hline y92 & -0.20 & 0.18 & 0.10 & 0.06 & -3434.9 & 3763.6 & -4695.8 & 177.7 \\
\hline y97 & -0.06 & 0.19 & 0.15 & 0.06 & 9484.7 & 5026.9 & 2386.8 & 2243.0 \\
\hline pshort77 & 0.14 & 0.09 & & & & & & \\
\hline & 0.00 & 0.07 & & & & & & \\
\hline 37 & 0.11 & 0.09 & -0.04 & 0.03 & 4644.4 & 944.1 & 4388.4 & 871.8 \\
\hline on & -0.01 & 0.09 & 0.00 & 0.02 & 4926.3 & 1559.3 & 4934.9 & 1403.5 \\
\hline pshort92 & 0.11 & 0.09 & -0.01 & 0.03 & 1099.9 & 1226.7 & 1701.2 & 1280.2 \\
\hline plong92 & -0.02 & 0.07 & 0.01 & 0.02 & -304.5 & 1690.4 & 1905.1 & 1640.0 \\
\hline 7 & 0.06 & 0.09 & 0.05 & 0.02 & 1946.4 & 1332.2 & 1657.7 & 1422.3 \\
\hline 7 & 0.07 & 0.08 & 0.06 & 0.02 & -1874.7 & 2249.7 & -1493.0 & 2039.2 \\
\hline & 0.0 & $0.2-2$. & & & & & & \\
\hline & -0.07 & 7 & & & & & & \\
\hline & -0.01 & 19 & & & & & & \\
\hline 77 & 0.11 & 16 & & & & & & \\
\hline 7 & -0.01 & 0.18 & -0.11 & 0.06 & 3720.1 & 2817.9 & 4245.5 & 2668.2 \\
\hline & -0.04 & 0.18 & -0.10 & 0.05 & -262.3 & 2282.7 & -524.8 & 2327.8 \\
\hline & -0.04 & 0.16 & -0.13 & 0.05 & 361.1 & 2298.7 & 622.9 & 2249.0 \\
\hline & 0.04 & 0.17 & -0.13 & 0.05 & 835.2 & 1933.1 & 796.5 & 1914.2 \\
\hline retail92 & 0.11 & 0.16 & -0.06 & 0.05 & 3010.1 & 2640.6 & 3643.9 & 2529.2 \\
\hline 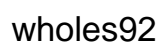 & 0.20 & 0.17 & -0.04 & 0.05 & 2300.3 & 2268.3 & 1688.9 & 2514.2 \\
\hline & 0.1 & 5 & -0.05 & 0.06 & 452.5 & 2498.4 & 994.5 & 2645.8 \\
\hline e92 & 0.3 & 0 & -0.09 & 0.05 & 1740.5 & 2027.9 & 1819.7 & 2207.2 \\
\hline & 0.1 & 0 & -0.14 & 0.05 & 588.9 & 2847.3 & 1099.6 & 2799.0 \\
\hline 597 & 0.05 & 0.20 & -0.10 & 0.06 & 1817.0 & 2436.2 & 1721.7 & 2561.3 \\
\hline manuf97 & 0.02 & 0.16 & -0.15 & 0.06 & 3730.3 & 3012.3 & 4221.6 & 3011.4 \\
\hline forhire97 & 0.19 & 0.16 & -0.17 & 0.05 & -1948.2 & 2600.9 & -1327.1 & 2641.9 \\
\hline length & & & & & 449.3 & 44.5 & & \\
\hline length87 & & & & & -204.3 & 71.0 & & \\
\hline length92 & & & & & -35.8 & 54.3 & & \\
\hline length97 & & & & & -161.8 & 76.8 & & \\
\hline farmpd & -0.07 & 0.09 & -0.01 & 0.03 & 8934.2 & 1330.8 & 9132.7 & 1410.3 \\
\hline
\end{tabular}




\begin{tabular}{|c|c|c|c|c|c|c|c|c|}
\hline \multirow{3}{*}{$\begin{array}{l}\text { prfood } \\
\text { bldgma }\end{array}$} & \multicolumn{2}{|c|}{ (1) } & \multicolumn{2}{|c|}{ (2) } & \multicolumn{2}{|c|}{ (3) } & \multicolumn{2}{|c|}{ (4) } \\
\hline & 0.12 & 0.03 & 0.07 & 0.01 & 5604.1 & 919.2 & 6306.0 & 952.4 \\
\hline & 0.06 & 0.06 & 0.06 & 0.03 & 3399.8 & 1451.3 & 3932.7 & 1516.2 \\
\hline paper & 0.09 & 0.04 & 0.05 & 0.01 & 299.8 & 1217.8 & 1446.2 & 1210.4 \\
\hline chem & -0.07 & 0.07 & 0.15 & 0.02 & 5370.8 & 1038.2 & 5915.4 & 1057.7 \\
\hline primtl & -0.13 & 0.11 & 0.12 & 0.03 & 5307.5 & 1400.1 & 6399.5 & 1485.4 \\
\hline fabmtl & -0.02 & 0.05 & 0.06 & 0.02 & -2269.8 & 1142.8 & -1609.9 & 1081.8 \\
\hline machne & -0.23 & 0.07 & 0.16 & 0.02 & -2455.6 & 1306.2 & -2523.8 & 1334.9 \\
\hline tequip & -0.02 & 0.06 & 0.10 & 0.01 & 122.4 & 1641.0 & 1015.3 & 1576.2 \\
\hline furn & -0.05 & 0.06 & 0.09 & 0.02 & -8508.6 & 1535.0 & -8190.2 & 1482.6 \\
\hline textil & 0.05 & 0.04 & 0.11 & 0.02 & -3366.6 & 1039.0 & -2764.6 & 1066.8 \\
\hline forest & 0.10 & 0.13 & 0.04 & 0.04 & 12710.9 & 3194.3 & 12767.3 & 3194.9 \\
\hline petroplast & 0.03 & 0.08 & 0.11 & 0.02 & -3081.2 & 2264.6 & -2901.4 & 2455.0 \\
\hline cons & 9.59 & 0.16 & 0.52 & 0.05 & 9783.1 & 2687.2 & 32997.8 & 1238.9 \\
\hline \multicolumn{2}{|c|}{ " Num of observations } & $\overline{23193}$ & & 11298 & & 17897 & & 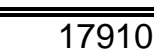 \\
\hline \multicolumn{2}{|c|}{ Num of strata } & & & 1 & & 1 & & \\
\hline \multicolumn{2}{|c|}{ Num of PSUs } & 157 & & 140 & & 140 & & 140 \\
\hline \multicolumn{2}{|c|}{ Population size } & 1078755 & & 497326.3 & & 770869.5 & & 771203.8 \\
\hline \multicolumn{2}{|c|}{$F(47,1000)$} & 237.39 & $F(40,68)$ & 60 & $F(44,96)$ & 45.57 & $F(40,100)$ & 34.74 \\
\hline \multicolumn{2}{|l|}{ R-squared } & 0.4227 & & 0.2312 & & 0.1497 & & 0.1248 \\
\hline
\end{tabular}

Bold faced coefficients are significant at the 95\% confidence level. 
Table 2

Trends in Ton-Miles per Truck and in Components of Ton-miles With Current Year and Constant Traffic Proportions.

\begin{tabular}{|c|c|c|c|c|c|}
\hline Averaging Method & 1982 & 1987 & 1992 & 1997 & $\begin{array}{c}\text { Average } \\
\text { annual } \\
\text { change }\end{array}$ \\
\hline & \multicolumn{5}{|c|}{ Probability of a truck operating with a load } \\
\hline Current year wtd average & 0.786 & 0.816 & 0.833 & 0.854 & $0.54 \%$ \\
\hline \multirow[t]{2}{*}{1982 weighted average } & 0.786 & 0.810 & 0.814 & 0.824 & $0.29 \%$ \\
\hline & \multicolumn{5}{|c|}{ Miles per truck } \\
\hline Current year wtd average & 63,628 & 72,043 & 73,998 & 82,053 & $1.58 \%$ \\
\hline \multirow[t]{2}{*}{1982 weighted average } & 63,628 & 68,819 & 69,201 & 74,933 & $0.99 \%$ \\
\hline & \multicolumn{5}{|c|}{ Net pounds per loaded truck } \\
\hline Current year wtd average & 41,262 & 43,966 & 39,594 & 42,046 & $-0.10 \%$ \\
\hline \multirow[t]{2}{*}{1982 weighted average } & 41,262 & 43,300 & 40,155 & 42,830 & $0.07 \%$ \\
\hline & \multicolumn{5}{|c|}{ Net pounds per loaded truck with truck length fixed at average 1982 size } \\
\hline Current year wtd average & 41,020 & 42,973 & 36,849 & 39,151 & $-0.59 \%$ \\
\hline \multirow[t]{2}{*}{1982 weighted average } & 41,020 & 42,366 & 37,644 & 40,198 & $-0.25 \%$ \\
\hline & \multicolumn{5}{|c|}{ Ton-miles per truck per year } \\
\hline Current year wtd average & $1,083,883$ & $1,363,378$ & $1,284,580$ & $1,506,009$ & $1.85 \%$ \\
\hline \multirow[t]{2}{*}{1982 weighted average } & $1,083,883$ & $1,281,773$ & $1,201,642$ & $1,376,665$ & $1.31 \%$ \\
\hline & \multicolumn{5}{|c|}{ Ton-miles per truck per year with truck length fixed at average 1982 size } \\
\hline Current year wtd average & $1,071,403$ & $1,326,451$ & $1,179,500$ & $1,390,393$ & $1.33 \%$ \\
\hline 1982 weighted average & $1,071,403$ & $1,247,620$ & $1,111,197$ & $1,280,750$ & $0.84 \%$ \\
\hline
\end{tabular}

Source: Calculations by authors. Growth rates are estimates from the regression of the natural logarithm of the dependent variable on an appropriate time trend. See text. 
Table 3

Aggregation shares and trends of ton-miles and determinants of ton-miles for fractions of truck traffic

\begin{tabular}{|c|c|c|c|c|c|c|c|c|c|}
\hline & $\begin{array}{c}1982 \\
\text { Tm/truck }\end{array}$ & $\begin{array}{c}82 \text { miles } \\
\text { share }\end{array}$ & $\begin{array}{c}97 \text { share } \\
\text { of miles }\end{array}$ & $\begin{array}{c}\text { miles } 77- \\
97 \\
\end{array}$ & loadfac & $\begin{array}{c}\text { wt|lngth- } \\
\text { const }\end{array}$ & weight & $\begin{array}{c}\text { TM } \\
\text { Ingth } \\
\text { const } \\
\end{array}$ & TM \\
\hline & (1) & (2) & (3) & $(4)$ & (5) & (6) & $(7)$ & $(8)$ & $(9)$ \\
\hline$\overline{\text { plocal }}$ & 229,340 & $13.31 \%$ & 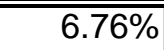 & $\overline{0.37 \%}$ & $0.08 \%$ & $\overline{-0.03 \%}$ & $\overline{0.33 \%}$ & $\overline{0.43 \%}$ & "0.80\% \\
\hline pshort & 568,675 & $28.03 \%$ & $24.96 \%$ & $0.25 \%$ & $0.48 \%$ & $0.07 \%$ & $0.42 \%$ & $1.29 \%$ & $1.64 \%$ \\
\hline plong & $1,524,098$ & $58.65 \%$ & $68.28 \%$ & $0.70 \%$ & $0.37 \%$ & $-0.67 \%$ & $-0.15 \%$ & $0.70 \%$ & $1.22 \%$ \\
\hline forhire & $1,184,725$ & $68.95 \%$ & $72.31 \%$ & $0.72 \%$ & $0.19 \%$ & $-0.61 \%$ & $-0.10 \%$ & $0.77 \%$ & $1.28 \%$ \\
\hline retail & 929,637 & $14.68 \%$ & $8.16 \%$ & $0.40 \%$ & $0.44 \%$ & $-0.22 \%$ & $0.25 \%$ & $0.97 \%$ & $1.44 \%$ \\
\hline wholesale & 819,631 & $9.63 \%$ & $6.76 \%$ & $0.58 \%$ & $0.79 \%$ & $0.19 \%$ & $0.50 \%$ & $1.24 \%$ & $1.55^{c}$ \\
\hline manufa & 874,146 & $4.27 \%$ & $4.91 \%$ & $-0.03 \%$ & $0.44 \%$ & $0.36 \%$ & $0.77 \%$ & $0.67 \%$ & $1.07 \%$ \\
\hline other & 578,392 & $2.47 \%$ & $7.85 \%$ & $-0.34 \%$ & $1.65 \%$ & $-0.20 \%$ & $0.12 \%$ & $0.91 \%$ & $1.23 \%$ \\
\hline farmpd & 741,695 & $1.99 \%$ & $1.84 \%$ & $0.37 \%$ & $0.60 \%$ & $-0.32 \%$ & $0.17 \%$ & $0.87 \%$ & 1.35 \\
\hline prfood & $1,113,305$ & $10.87 \%$ & $11.31 \%$ & $0.45 \%$ & $0.43 \%$ & $-0.16 \%$ & $0.25 \%$ & $0.91 \%$ & 1.310 \\
\hline bldgma & $1,132,266$ & $2.05 \%$ & $1.57 \%$ & $0.60 \%$ & $0.36 \%$ & $-0.55 \%$ & $-0.07 \%$ & $0.78 \%$ & 1.270 \\
\hline paper & $1,097,078$ & $5.78 \%$ & $10.54 \%$ & $0.63 \%$ & $0.32 \%$ & $-0.56 \%$ & $-0.03 \%$ & $0.75 \%$ & $1.28 \%$ \\
\hline chem & $1,064,149$ & $2.66 \%$ & $2.88 \%$ & $0.55 \%$ & $0.31 \%$ & $-0.39 \%$ & $0.06 \%$ & $0.85 \%$ & 1.29 \\
\hline primtl & $1,137,312$ & $1.79 \%$ & $2.29 \%$ & $0.56 \%$ & $0.37 \%$ & $-0.44 \%$ & $0.01 \%$ & $0.82 \%$ & 1.27 \\
\hline fabmtl & $1,119,179$ & $3.04 \%$ & $2.56 \%$ & $0.59 \%$ & $0.33 \%$ & $-0.53 \%$ & $0.03 \%$ & $0.78 \%$ & 1.33 \\
\hline machne & 898,861 & $1.40 \%$ & $3.70 \%$ & $0.58 \%$ & $0.35 \%$ & $-0.58 \%$ & $-0.01 \%$ & $0.68 \%$ & 1.24 \\
\hline tequip & $1,074,754$ & $1.73 \%$ & $5.31 \%$ & $0.60 \%$ & $0.36 \%$ & $-0.57 \%$ & $-0.04 \%$ & $0.72 \%$ & 1.260 \\
\hline furn & 826,587 & $2.54 \%$ & $4.05 \%$ & $0.64 \%$ & $0.31 \%$ & $-0.72 \%$ & $-0.02 \%$ & $0.56 \%$ & $1.27 \mathrm{C}$ \\
\hline textil & 975,538 & $3.12 \%$ & $5.13 \%$ & $0.57 \%$ & $0.36 \%$ & $-0.50 \%$ & $0.07 \%$ & $0.72 \%$ & 1.290 \\
\hline forest & $1,253,681$ & $0.14 \%$ & $0.28 \%$ & $0.63 \%$ & $0.27 \%$ & $-0.37 \%$ & $0.01 \%$ & $0.97 \%$ & 1.350 \\
\hline petroplast & $1,127,693$ & $0.73 \%$ & $2.05 \%$ & $0.67 \%$ & $0.23 \%$ & $-0.69 \%$ & $-0.08 \%$ & $0.64 \%$ & 1.250 \\
\hline othcom & $1,112,752$ & $62.16 \%$ & $46.49 \%$ & $0.56 \%$ & $0.39 \%$ & $-0.42 \%$ & $0.00 \%$ & $0.89 \%$ & $1.31 \%$ \\
\hline
\end{tabular}

Source: Calculations by authors. See text. 